\title{
Age-stratified sex differences in polysomnographic findings and pharyngeal morphology among children with obstructive sleep apnea
}

\author{
Ayako Inoshita ${ }^{1,2}$, Takatoshi Kasai ${ }^{2,3,4}$, Rina Matsuoka ${ }^{1}$, Naoko Sata ${ }^{1,2}$, Nanako Shiroshita ${ }^{3}$, Fusae Kawana ${ }^{3}$, \\ Mitsue Kato ${ }^{3}$, Katsuhisa Ikeda ${ }^{1}$ \\ ${ }^{1}$ Department of Otorhinolaryngology, Head and Neck Surgery, Juntendo University School of Medicine, Tokyo, Japan; ${ }^{2}$ Sleep and Sleep-Disordered \\ Breathing Center, Juntendo University Hospital, Tokyo, Japan; ${ }^{3}$ Cardiovascular Respiratory Sleep Medicine, Juntendo University Graduate School \\ of Medicine, Tokyo, Japan; ${ }^{4}$ Department of Cardiovascular Medicine, Juntendo University School of Medicine, Tokyo, Japan \\ Contributions: (I) Conception and design: All authors; (II) Administrative support: None; (III) Provision of study materials or patients: None; \\ (IV) Collection and assembly of data: All authors; (V) Data analysis and interpretation: All authors; (VI) Manuscript writing: All authors; (VII) Final \\ approval of manuscript: All authors. \\ Correspondence to: Ayako Inoshita. Department of Otorhinolaryngology, Head and Neck Surgery, Juntendo University School of Medicine, 2-1-1 \\ Hongo, Bunkyo-ku, Tokyo 113-8421, Japan. Email: ayaent@juntendo.ac.jp.
}

Background: Childhood obstructive sleep apnea (OSA) has important implications for growth, learning, behavior, cognition and cardiovascular health as well as snoring and OSA in adulthood. In this study, we elucidated the sex differences in polysomnographic (PSG) findings and pharyngeal radiographic data in pediatric OSA patients.

Methods: Sixty three children (age between 3 and 15 years old) with OSA [defined as apnea-hypopnea index $(\mathrm{AHI}) \geq 1 / \mathrm{h}$ by polysomnography] were enrolled. Lateral neck radiographs were obtained from the patients. All subjects were separated by age: pre-adolescent group (3-8 years old) and adolescent group (9-15 years old).

Results: Overall, 45 patients in the pre-adolescent group (33 boys and 12 girls) and 18 patients in the adolescent group (10 boys and 8 girls) were enrolled, and sex differences were compared in each group. We found sex differences in craniofacial features and severity of OSA in the adolescent group, in which girls with OSA had more upper airway space, in addition to lower AHI, lower 3\% oxygen desaturation index (ODI), higher minimum $\mathrm{SO}_{2}$ and better sleep efficiency than the boys.

Conclusions: The present study found revealed sex differences in pediatric OSA patients in the adolescent group. Girls in the adolescent group had more upper airway space in addition to lower AHI, lower 3\% ODI, higher minimum $\mathrm{SO}_{2}$ and better sleep efficiency than boys.

Keywords: Sex differences; obstructive sleep apnea (OSA); adenotonsillar tissue; polysomnography; upper airway

Submitted Jun 26, 2018. Accepted for publication Oct 17, 2018.

doi: $10.21037 /$ jtd.2018.11.09

View this article at: http://dx.doi.org/10.21037/jtd.2018.11.09

\section{Introduction}

Obstructive sleep apnea (OSA) is one of the important public health concerns in children since OSA is known to result in behavioral and cognitive impairments, and physiological deficits, worsening the quality of life (QOL) $(1,2)$. In addition, OSA can also have a negative impact on cardiovascular and metabolic systems even in childhood (2). The negative impact of OSA may not simply be confined to the short-term wellness and development during childhood, but may continue adversely affecting the long-term wellness even in adulthood (JCH). The recurrent obstruction of the upper airway during sleep evokes to intermittent 
oxygen desaturation, intrathoracic pressure changes, and repetitive arousals, which contribute to the alteration of systemic blood pressure and promote target-organ damage through heterogeneous and synergetic mechanisms (3). The prevalence of OSA in children has been reported to be $1-6 \%(1,4)$ and varies according to the age group; up to $6 \%$ among preschooler children, $4.7 \%$ among $8-11$ years old and $4.3 \%$ in those 16-19 years old (4-6), suggesting that the prevalence of OSA declines with growth. Adenotonsillar hypertrophy plays an important role in the pathogenesis of childhood OSA (7). Thus, adenotonsillectomy (AT) provides resolution of childhood OSA in cases with adenotonsillar hypertrophy. Indeed, AT is regarded as the first-line treatment for children with OSA and adenotonsillar hypertrophy (8). However, some adolescents may reveal spontaneous resolution of OSA. A previous study, based on the Childhood Adenotonsillectomy (CHAT) study data, reported that, among patients with mild to moderate OSA, normalization of polysomnographic (PSG) findings was observed in $76 \%$ of 5 - to 9 -year old children in the earlyAT group, whereas $46 \%$ of children in the watchful waiting group showed spontaneous resolution of OSA (9). On the other hand, adolescent boys were more likely to suffer from OSA than girls in a study describing that more than onethird of the boys without OSA at the baseline progressed to OSA [defined as an obstructive apnea-hypopnea index (AHI) $\geq 1$ event per hour by home PSG] in a 5 -year follow-up period (10). In general, males were associated with a higher incidence of (persistent) OSA around middle childhood and late adolescence when OSA was evaluated by questionnaire and sleep study (6).

In adults, obvious gender differences in the prevalence and severity of OSA were reported. OSA is $2-3$ times more prevalent in men than in women (11). Such male predominance also occurs in young adults (i.e., when premenopausal women and men of similar age are compared), whereas the prevalence of OSA in postmenopausal women approaches that of men of similar age (12). The menopause transition is significantly associated with an increased likelihood of OSA $(13,14)$. These findings suggest that reductions in the secretion of estrogen and/or progesterone in women may play a role in the sex difference in the prevalence and severity of OSA, and that estrogen and/or progesterone may be protective against OSA (15). Given such sex differences in adulthood OSA, there might be similar sex differences in childhood OSA resulting from the greater secretion of estrogen and/ or progesterone around age of puberty in girls.
On the other hand, spontaneous remission of hypertrophied adenotonsillar tissues has been known to occur before the onset of puberty $(16,17)$. There is a possibility for spontaneous resolution of OSA before middle adolescence. Thus, we hypothesized that a sex difference in OSA existed among children after the age of puberty, whereas such sex difference in OSA would not be observed among children before the age of puberty. To test this hypothesis, we compared anthropometric data, sleep study data and radiographic parameters in girls with those in boys during early and middle childhood.

\section{Methods}

\section{Subjects}

In this retrospective study, sixty three Japanese children (age between 3 and 15 years old) who visited our institution (Department of Otorhinolaryngology, Head and Neck Surgery at Juntendo University Hospital, Tokyo, Japan) because of snoring, apparent apnea, with and without sleepiness, and who were diagnosed as having OSA defined as $\geq 1$ apnea or hypopnea events per hour of sleep (i.e., the AHI) by overnight polysomnography, were enrolled between January 2014 and December 2015. Symptoms of sleepiness were follows: (I) need for daytime naps; (II) awaking confused or disoriented; and (III) restlessness. To eliminate any potential confounding factors in the clinical features, only Japanese children were included. Other exclusion criteria were as follows: (I) a history of pharyngeal surgery or orthognathic surgery; (II) treatment for sleep-disordered breathing, including use of oral appliances, oxygen inhalation, and positive airway pressure therapy prior to the sleep study; and (III) refusal to undergo pharyngeal radiography. All children underwent otorhinolaryngologic examination at the outpatient clinic in our institution and physical examination was carried out by experienced otolaryngologists in each child to assess their physical state, height and weight, tonsil size. Body mass index (BMI) $\left(\mathrm{kg} / \mathrm{m}^{2}\right)$, based on direct height and weight measurements, was converted to age- and sexadjusted percentiles. BMI $\geq 95$ th percentile for age and sex was defined as obesity. The growth charts cited were from the website of Japanese Society for Pediatric Endocrinology (http://jspe.umin.jp/medical/taikaku.html). Tonsil size was graded using a point scale as previously reported (18).

Taking into consideration the age when spontaneous remission of hypertrophied adenotonsillar tissues can 

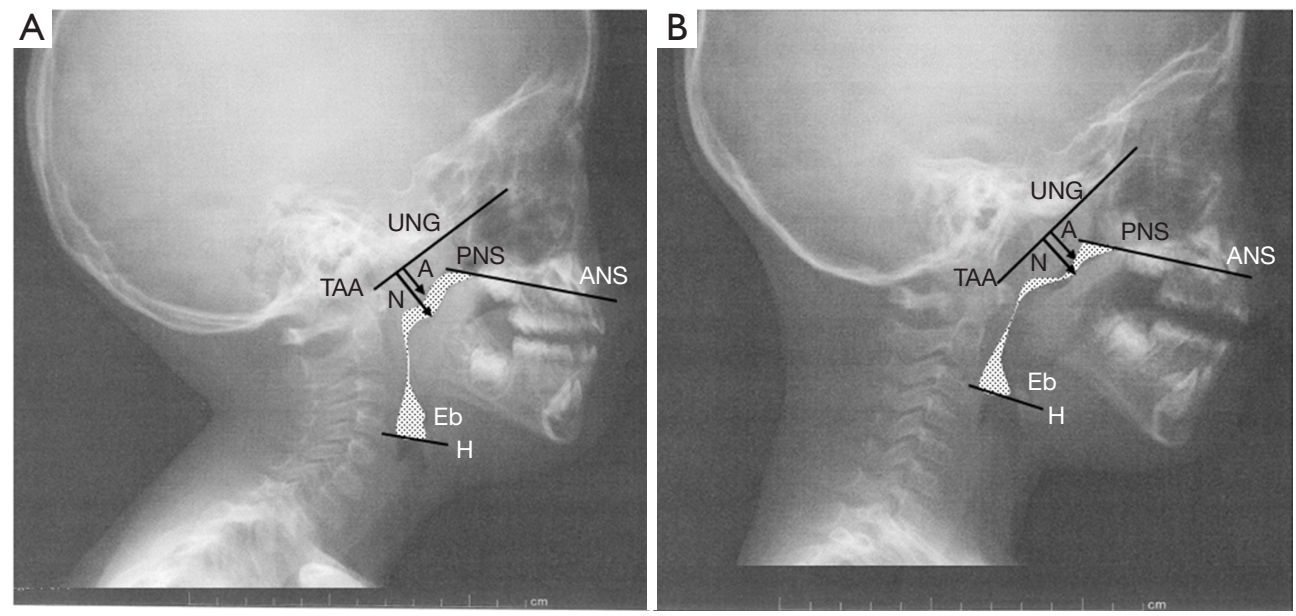

Figure 1 Representative radiography in 5-year old boy and girl. The airway area is shown as a dotted area. Diameter of adenoids and nasopharynx are shown as headed arrows, A and N. (A) Male OSA patient in pre-adolescent group. Airway area $=3.40 \mathrm{~cm}^{2}, \mathrm{~A} / \mathrm{N}$ ratio $=0.65$. AHI $=36.9 / \mathrm{h}$; (B) female OSA patient in pre-adolescent group. Airway area $=4.61 \mathrm{~cm}^{2}, \mathrm{~A} / \mathrm{N} \mathrm{ratio}=0.81$. AHI =20.1/h. ANS, anterior nasal spine; PNS, posterior nasal spine; H, hyoid bone; Eb, base of epiglottis; TAA, tuberculum anterius atlantis; UNG, upper edge of nasopharyngeal groove; A, diameter of adenoids; N, diameter of nasopharynx; OSA, obstructive sleep apnea; AHI, apnea-hypopnea index.

occur and the onset of puberty $(16,17)$, all subjects were separated by age, children at 3-8 years of age (i.e., preadolescent group) and children at $9-15$ years of age (i.e., adolescent group). The clinical characteristics, PSG parameters and lateral neck radiograph findings were compared between boys and girls within each group. This study was approved by the Ethics Committee at Juntendo Hospital (number 16-092).

\section{Sleep study}

All children underwent overnight polysomnography, and signals were recorded by standard techniques on a computerized sleep recording system using a digital polygraph (Alice 5; Philips Respironics, PA, USA). Recordings were scored following standard scoring rules (update of the 2012 American Academy of Sleep Medicine (AASM) Manual for the Scoring of Sleep and Associated Events) (19).

\section{Lateral neck radiograph}

Lateral neck radiograph was obtained for each patient in the upright position with natural head posture. Before the exposure, all patients were instructed to extend their neck. The distance between the source of radiation and the film was $150 \mathrm{~cm}$ with a flat panel detector.
Digital images were processed using an image processing program (ImageJ; National Institutes of Health, Bethesda, $\mathrm{MD})$. For measuring the upper airway area, the exposure parameters were arranged to clearly visualize bony landmarks (see Figures 1,2). As illustrated in Figure 1A, the following three radiographic variables, (I) anterior nasal spine (ANS), (II) posterior nasal spine (PNS), (III) hyoid bone $(\mathrm{H})$ and base of epiglottis $(\mathrm{Eb})$, were mapped to measure the upper airway space area, as described in our previous report (20). The adenoid-nasopharyngeal (A/N) ratio was measured according to the method of a previous report as illustrated in Figure $1 B$ (21). All measurements were done blindly and in a random order by a single investigator. Every measurement was made 3 times, and the mean value of the two most proximate measurements was used for the final analyses to ensure reliability.

\section{Statistical analysis}

Continuous variables are shown as mean \pm SD or median (interquartile range) as appropriate, and categorical variables are shown as numbers and percentages. For comparison of continuous variables, the Student's $t$-test for normally distributed data or the Mann-Whitney $U$-test for non-normally distributed data was used, and the Chi-square test or Fisher's exact test was used for categorical variables.

A P value of less than 0.05 was considered statistically 

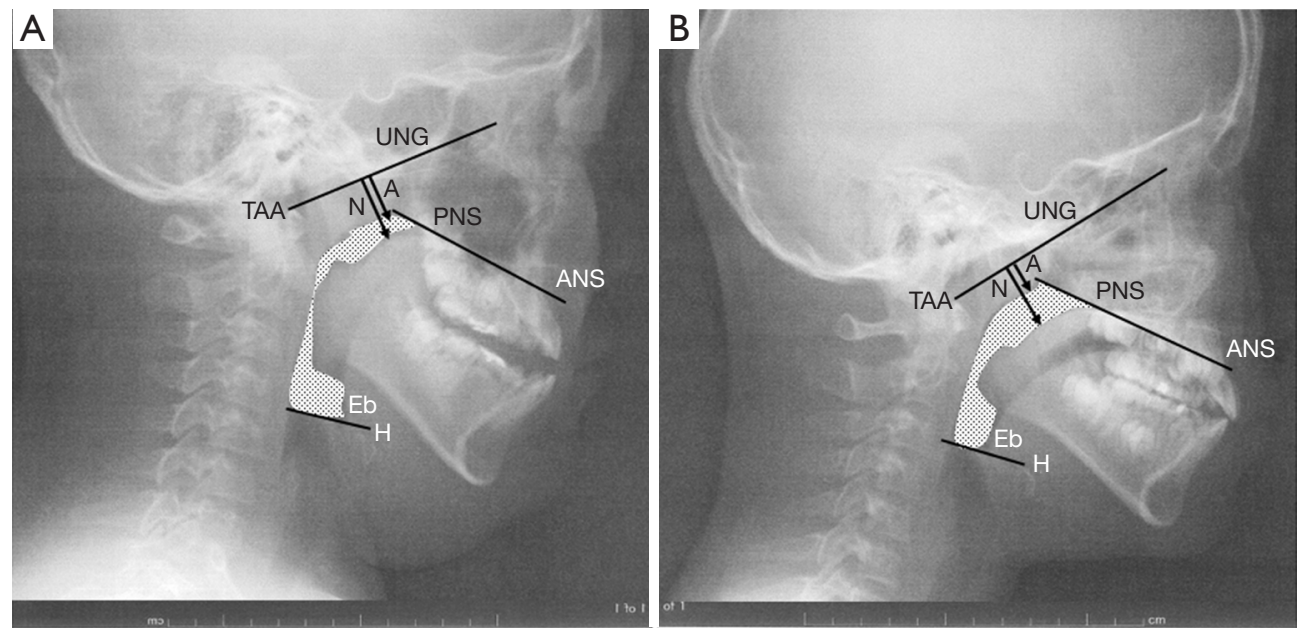

Figure 2 Representative radiography in 10-year old boy and girl. The airway area is shown as a dotted area. Diameter of adenoids and nasopharynx are shown as headed arrows, A and N. (A) Male OSA patient in adolescent group. Airway area $=3.56 \mathrm{~cm}^{2}, \mathrm{~A} / \mathrm{N} \mathrm{ratio}=0.67$. AHI $=9.7 / \mathrm{h}$; (B) female OSA patient in adolescent group. Airway area $=6.31 \mathrm{~cm}^{2}, \mathrm{~A} / \mathrm{N}$ ratio $=0.39$. AHI $=2.3 / \mathrm{h}$. ANS, anterior nasal spine; PNS, posterior nasal spine; $\mathrm{H}$, hyoid bone; Eb, base of epiglottis; TAA, tuberculum anterius atlantis; UNG, upper edge of nasopharyngeal groove; A, diameter of adenoids; N, diameter of nasopharynx; OSA, obstructive sleep apnea; AHI, apnea-hypopnea index.

Table 1 Characteristics of pre-adolescents

\begin{tabular}{lccc}
\hline Characteristics & Male $(\mathrm{n}=33)$ & Female $(\mathrm{n}=12)$ & $\mathrm{P}$ value \\
\hline Age, years & $4.7 \pm 1.3$ & $4.9 \pm 1.6$ & $15.3 \pm 1.1$ \\
BMI, kg/m ${ }^{2}$ & $16.2 \pm 3.5$ & $-0.07 \pm 0.97$ & 0.438 \\
BMI z-score & $0.02 \pm 0.86$ & $1(8.3)$ & 0.815 \\
Obese (BMI >95\%), No. (\%) & $4(12.1)$ & & 0.721 \\
Tonsillar size, No. (\%) & & $0(0.0)$ \\
Grade 0 & $0(0.0)$ & $0(0.0)$ & 0.542 \\
Grade 1 & $1(3.0)$ & $0(0.0)$ & 0.502 \\
Grade 2 & $4(12.1)$ & $8(66.7)$ & 0.199 \\
Grade 3 & $13(39.4)$ & $4(33.3)$ & 0.699 \\
Grade 4 & $15(45.5)$ & $1(8.3)$ & 0.937 \\
Sleepiness, No. (\%) & $3(9.1)$ & $3(25.0)$ & 0.958 \\
History of rhinitis, No. (\%) & $8(24.2)$ & \\
\hline
\end{tabular}

BMI, body mass index.

significant. All statistical analyses were performed using the statistical software package GraphPad PRISM version 6.05 (GraphPad Software, Inc., La Jolla, CA, USA).

\section{Results}

Data of 45 patients in the pre-adolescent group (33 boys and 12 girls) and 18 patients in the adolescent group (10 boys and 8 girls) were evaluated. The clinical characteristics of the patients are shown in Tables 1 and 2. There were no significant differences in clinical characteristics between the boys and girls in either the preadolescent or adolescent group.

PSG parameters are shown in Tables 3 and 4 . In the pre- 
Table 2 Characteristics of adolescents

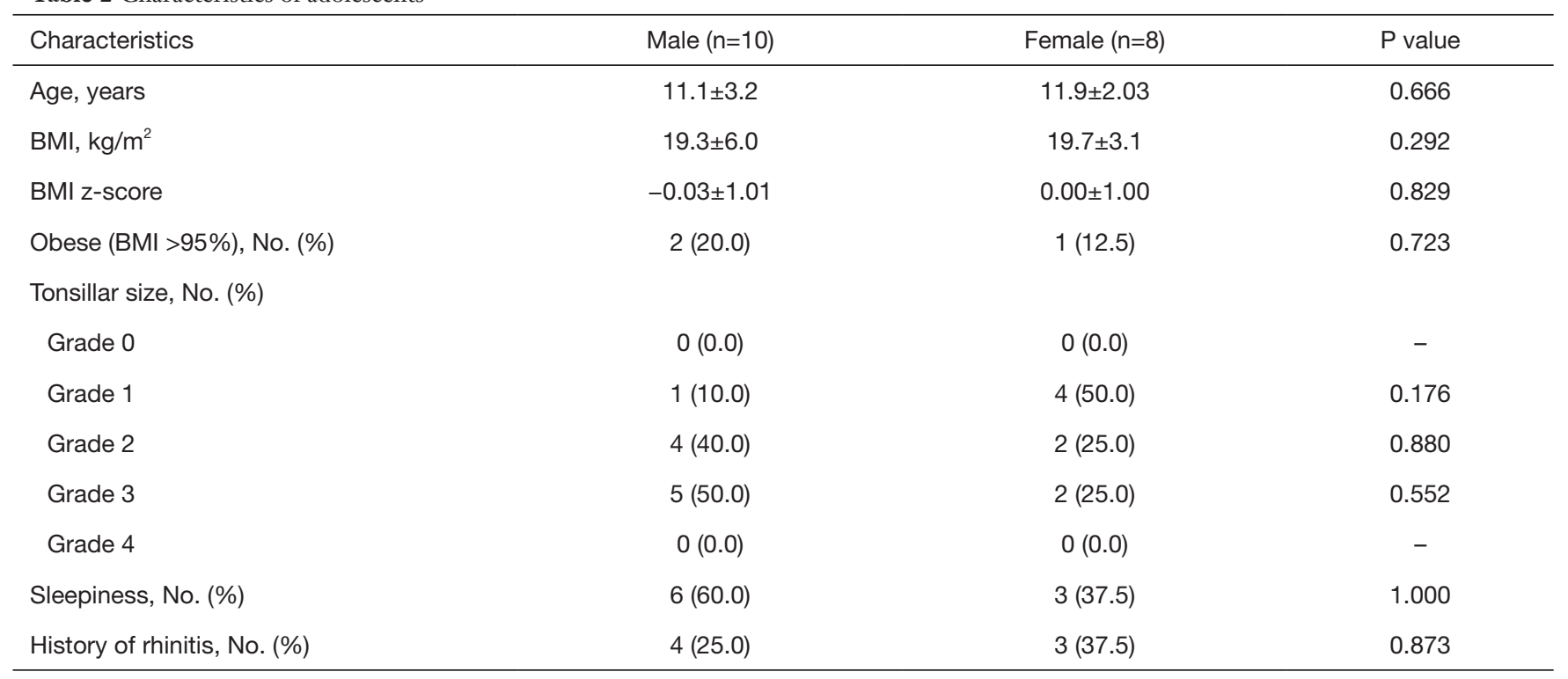

BMI, body mass index.

Table 3 PSG findings of pre-adolescents

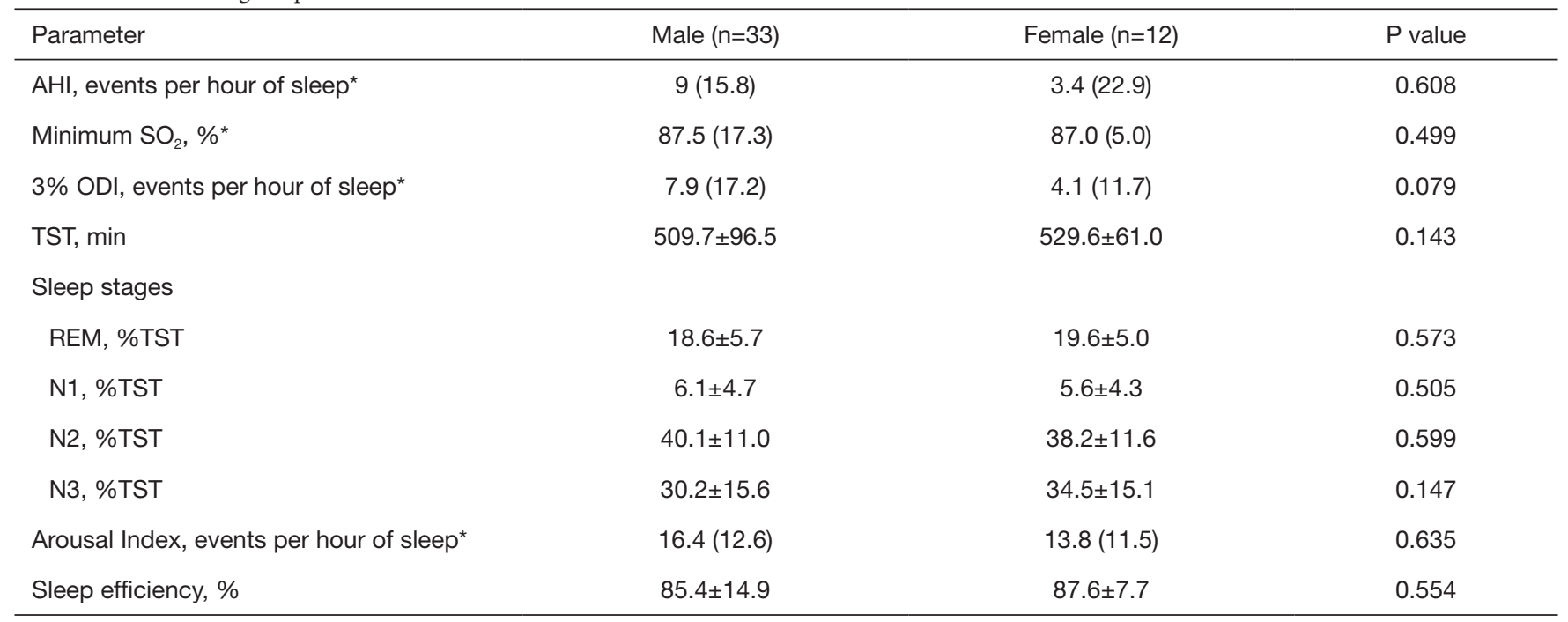

*, values are expressed as mean \pm SD or median (interquartile range). PSG, polysomnographic; BMI, body mass index; AHI, apneahypopnea index, $\mathrm{SO}_{2}$, oxyhemoglobin saturation; ODI, oxygen desaturation index; REM, rapid eye movement.

adolescent group, there were no significant differences in the PSG parameters between the boys and girls. However, in the adolescent group, girls had significantly lower AHI and $3 \%$ oxygen desaturation index (ODI), and greater minimum level of oxyhemoglobin saturation $\left(\mathrm{SO}_{2}\right)$ and sleep efficiency compared with the boys. In the adolescent group, other parameters of girls were similar to those of boys.
Representative radiographs of children in the preadolescent and adolescent groups are shown in Figures 1 and 2, respectively. The radiographic parameters are summarized in Tables 5 and 6 . In the pre-adolescent group, no significant differences between the boys and girls were observed. However, in the adolescents group, the girls had significantly greater upper airway area and lower $\mathrm{A} / \mathrm{N}$ ratio 
Table 4 PSG findings of adolescents

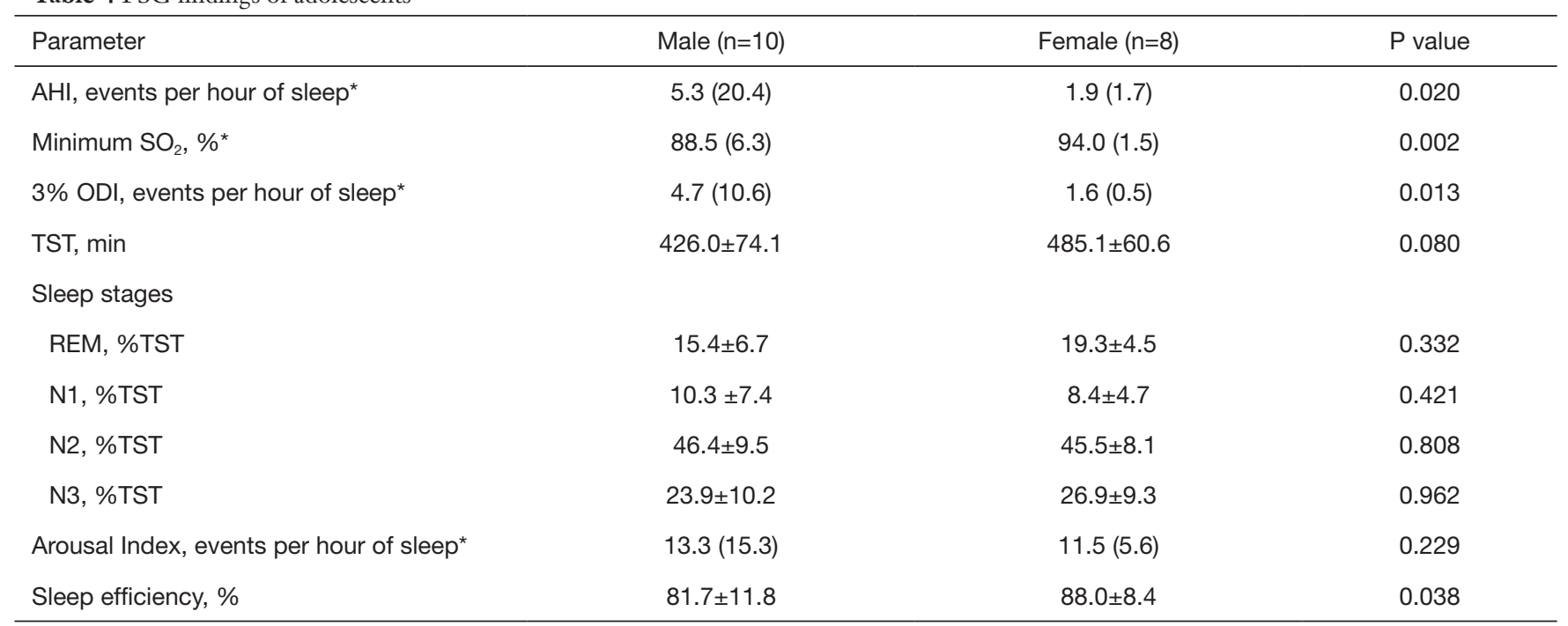

*, values are expressed as mean \pm SD or median (interquartile range). PSG, polysomnographic; BMI, body mass index; AHI, apneahypopnea index, $\mathrm{SO}_{2}$, oxyhemoglobin saturation; ODI, oxygen desaturation index; REM, rapid eye movement.

Table 5 Radiographic findings of pre-adolescents

\begin{tabular}{lccc}
\hline Characteristics & Male $(\mathrm{n}=33)$ & Female $(\mathrm{n}=12)$ & $\mathrm{P}$ value \\
\hline Upper airway are $\left(\mathrm{cm}^{2}\right)$ & $3.47(0.97)$ & $3.22(0.99)$ & 0.468 \\
A/N ratio & $0.67(0.23)$ & $0.74(0.16)$ & 0.223 \\
\hline
\end{tabular}

Values are expressed as median (interquartile range). $\mathrm{A} / \mathrm{N}$ ratio, adenoid/nasopharyngeal ratio.

compared with the boys.

\section{Discussion}

In this study, we investigated sex differences in the PSG and radiographic data in both pre-adolescents with OSA and adolescents with OSA. In terms of the PSG data, in the adolescent group, girls had significantly lower AHI and $3 \%$ ODI, higher minimum $\mathrm{SpO}_{2}$ and better sleep efficiency than the boys, whereas in the pre-adolescent group, no such differences between boys and girls were observed. In the radiographic assessments, the girls showed significantly lower $\mathrm{A} / \mathrm{N}$ ratio and upper airway area than the boys in the adolescents group, whereas we did not find any significant sex differences in the radiographic parameters of the pre-adolescent group. These findings suggested that sex differences in the severity of OSA can be more prominent or exclusively observed in adolescents compared with pre-adolescents in association with changes in the
Table 6 Radiographic findings of adolescents

\begin{tabular}{lccc}
\hline Characteristics & Male $(\mathrm{n}=16)$ & Female $(\mathrm{n}=8)$ & $\mathrm{P}$ value \\
\hline Upper airway area $\left(\mathrm{cm}^{2}\right)$ & $5.58(0.99)$ & $6.92(0.50)$ & 0.005 \\
A/N ratio & $0.67(0.09)$ & $0.35(0.14)$ & 0.018 \\
\hline \multicolumn{4}{l}{$\begin{array}{l}\text { Values are expressed as median (interquartile range). A/N ratio, } \\
\text { adenoid/nasopharyngeal ratio. }\end{array}$}
\end{tabular}

upper airway morphology, possibly due to the regression of adenotonsillar hypertrophy in girls. To our knowledge, this is the first report of OSA from early to middle childhood and its associated risks that addresses sex differences using pharyngeal analyses.

The commonest cause of OSA is adenotonsillar hypertrophy, which causes a collapsing of the pharynx in the pediatric population. Some reports indicated that OSA appeared in young children due to adenotonsillar hypertrophy (22). The peak size for tonsils is reported to occur in children around 4 to 8 years old, and the adenotonsillar tissues usually undergo remission by the age of puberty. Spontaneous improvement of OSA in middle childhood has been reported in studies that evaluated patients by questionnaire, physical examination and home PSG (10). Valera et al. and Don et al. observed a higher tendency for OSA in young children with adenotonsillar hypertrophy than in older ones $(22,23)$. Taken together, these previous findings indicated that a more obvious association between adenotonsillar 
hypertrophy and OSA exists in pre-adolescents than in adolescents. Our results support these previous findings that the upper airway area and $\mathrm{A} / \mathrm{N}$ ratio findings showed no significant differences in pre-adolescents.

In terms of the risk factors for older pediatric OSA, airway size and body fat increase have been described $(8,24)$. In general, middle to late adolescent boys have shown a stronger association with the incidence of OSA compared to girls by questionnaire and PSG $(8,24)$. Previous findings also suggested that some children will be found to have OSA regardless of gender based on PSG even after the peak age of adenotonsillar tissues, but the upper airway morphology was not specifically evaluated (6). Furthermore, how this affects sex differences remains unclear. In the present study, although there were no significant differences in upper airway morphology between pre-adolescent boys and girls, adolescent boys had significant smaller upper airway areas and greater $\mathrm{A} / \mathrm{N}$ ratio compared with adolescent girls, suggesting that girls may have spontaneous remission of adenoid tissues but boys do not. There might be a possibility that estrogen may be associated with the remission of adenotonsil tissues at puberty.

The finding regarding male predominance in the severity of OSA in adolescent children is similar to the male predominance in adult OSA. On the other hand, it is known that the prevalence of OSA in post-menopausal women is greater compared with that in premenopausal women, but the prevalence of OSA is consistently higher in men $(11,25)$. In previous studies regarding sex differences in adult OSA, one possible explanation for such sex differences is that the longer airway in men could lead to an increased propensity for airway collapse (26). Indeed, the passive pharyngeal airway collapsing pressure was generally higher in men than in women (27). In addition, men consistently had larger total oropharynx length and volume than women even in the Japanese population (28). Furthermore, women generally had better respiratory load responses than men, possibly in association with greater levels of female hormones such as estrogen and progesterone (24). Moreover, hormone replacement therapy (HRT) appears to markedly reduce AHI during sleep (29). These suggest that alterations in the secretion of female hormones may play some roles in the OSA pathogenesis in women. Considering these and findings of the present study that male predominance was observed only in adolescent children, increased secretion of female hormones in adolescent girls may affect the respiratory load responses and reduce the AHI. The mechanisms by which female hormones may affect adenotonsillar tissues have not been elucidated. Although the expression of estrogen receptors in adults has not been reported, estrogen receptors were found to be expressed in 2- to 3-year old children tonsils (30). Taken together, our findings suggested that the presence and severity of OSA may alter according to the stage of puberty.

Concerning the treatment of childhood OSA, the majority of cases are amenable to a surgical approach. However, OSA occurs in approximately $20 \%$ of normalweight children even after AT and, in nearly $70 \%$ of them, residual OSA may be caused by adenoid regrowth (31). Spilsbury et al. reported that children with severe or moderate OSA had a high incidence of persistent SDB even after (6). Males are known to have a greater risk of persistent OSA (6). These findings suggest that, for preadolescent boys, early-AT should be considered but, for pre-adolescent girls, watchful waiting should be considered.

The present study has certain limitations. First, we did not follow the same patients through pre-adolescent to adolescent periods. AT is commonly performed for pediatric OSA. Thus, in many pediatric OSA children surgical treatment tends to be chosen at the time of diagnosis. That is the reason why it is difficult to follow pediatric patients without surgical treatment for years. Second, the number of subjects, especially in the adolescent group, is small. Since patients included in pre-adolescents group may have had spontaneous resolution of OSA, we could not find sufficient numbers of participants in the adolescent group. Finally, only radiographic data were collected. It is important to know about sex differences of the craniofacial anatomy determined by cephalometry, computed tomography or magnetic resonance imaging. We did not collect blood sample for sex hormones in this study. In consideration of children, saliva test would be easily possible to check the hormones. Although this is just a pilot study, we provide a new hypothesis regarding the male predominance of OSA in adolescent children despite the lack of such sex differences in pre-adolescent children. Further experiments would be required such as serum or saliva sex hormone levels to confirm our hypothesis. This may possibly occur in association with the more obvious spontaneous remission of adenotonsillar tissue in adolescent girls. Further study is needed to confirm this hypothesis.

\section{Conclusions}

The present study revealed sex differences in adolescent OSA patients despite the lack of such differences in pre- 
adolescent OSA. In addition, adolescent girls with OSA had greater upper airway space in addition to have less severe OSA and better sleep efficiency compared with adolescent boys with OSA.

\section{Acknowledgements}

Funding: This work was supported by research grants from Institute for Environmental and Gender Specific Medicine in Juntendo University [grant number E2823]. The sponsor had no role in the design or conduct of this research.

\section{Footnote}

Conflicts of Interest: The authors have no conflicts of interest to declare.

Ethical Statement: All procedures performed in studies involving human participants were in accordance with the ethical standards of the institutional and/or national research committee and with the 1964 Helsinki declaration and its later amendments or comparable ethical standards. This study was approved by the Ethics Committee at Juntendo Hospital (number 16-092).

\section{References}

1. Marcus CL, Brooks LJ, Draper KA, et al. Diagnosis and management of childhood obstructive sleep apnea syndrome. Pediatrics 2012;130:714-55.

2. American Thoracic Society. Standards and indications for cardiopulmonary sleep studies in children. Am J Respir Crit Care Med 1996;153:866-78.

3. Lattanzi S, Francesco B, Silvestrini M. Obstructive sleep apnea syndrome and the nocturnal blood pressure profile. J Clin Hypertens (Greenwich) 2018;20:1036-8.

4. Lumeng JC, Chervin RD. Epidemiology of pediatric obstructive sleep apnea. Proc Am Thorac Soc 2008;5:242-52.

5. Rosen CL, Larkin EK, Kirchner HL, et al. Prevalence and risk factors for sleep-disordered breathing in 8- to 11-yearold children: association with race and prematurity. $\mathrm{J}$ Pediatr 2003;142:383-9.

6. Spilsbury JC, Storfer-Isser A, Rosen CL, et al. Remission and incidence of obstructive sleep apnea from middle childhood to late adolescence. SLEEP 2015;38:23-9.

7. Kang KT, Chou CH, Weng WC, et al. Associations between adenotonsillar hypertrophy, age, and obesity in children with obstructive sleep apnea. PLoS One 2013;8:e78666.

8. Weatherly RA, Mai EF, Ruzicka DL, et al. Identification and evaluation of obstructive sleep apnea prior to adenotonsillectomy in children: a survey of practice patterns. Sleep Med 2003;4:297-307.

9. Marcus CL, Moore RH, Rosen CL, et al. A randomized trial of adenotonsillectomy for childhood sleep apnea. $\mathrm{N}$ Engl J Med 2013;368:2366-76.

10. Goodwin JL, Vasquez MM, Silva GE, et al. Incidence and remission of sleep-disordered breathing and related symptoms in 6- to 17-year old children--the Tucson children's assessment of sleep apnea study. J Pediatr 2010;157:57-61.

11. Young T, Palta M, Dempsey J, et al. The occurrence of sleep-disordered breathing among middle-aged adults. N Engl J Med 1993;328:1230-5.

12. Kapsimalis F, Kryger MH. Gender and obstructive sleep apnea syndrome, part 1: Clinical features. Sleep 2002;25:412-9.

13. Yamakoshi S, Kasai T, Tomita Y, et al. Comparison of clinical features and polysomnographic findings between men and women with sleep apnea. J Thorac Dis 2016;8:145-51.

14. Pickett CK, Regensteiner JG, Woodard WD, et al. Progestin and estrogen reduce sleep-disordered breathing in postmenopausal women. J Appl Physiol 1989;66:1656-61.

15. Mirer AG, Peppard PE, Palta M, et al. Menopausal hormone therapy and sleep-disordered breathing: evidence for a healthy user bias. Ann Epidemiol 2015;25:779-84.e1.

16. Strayer DS. Rubin's Pathology, 7th Ed. LWW, USA, 2014.

17. Williams RH, Wilson JD. Williams Textbook of Endocrinology, 9th Ed. Saunders, 1998.

18. Brodsky L. Modern assessment of tonsils and adenoids. Pediatr Clin North Am 1989;36:1551-69.

19. Berry RB, Budhiraja R, Gottlieb DJ, et al. Rules for scoring respiratory events in sleep: update of the 2007 AASM Manual for the Scoring of Sleep and Associated Events. Deliberations of the Sleep Apnea Definitions Task Force of the American Academy of Sleep Medicine. J Clin Sleep Med 2012;8:597-619.

20. Inoshita A, Kasai T, Takahashi M, et al. Craniofacial anatomical risk factors in men with obstructive sleep apnea and heart failure: a pilot study. Sleep Breath 2014;18:439-45.

21. Li AM, Wong E, Kew J, et al. Use of tonsil size in the 
evaluation of obstructive sleep apnoea. Arch Dis Child 2002;87:156-9.

22. Valera FC, Avelino MA, Pettermann MB, et al. OSAS in children: correlation between endoscopic and polysomnographic findings. Otolaryngol Head Neck Surg 2005;132:268-72.

23. Don DM, Geller KA, Koempel JA, et al. Age specific differences in pediatric obstructive sleep apnea. Int J Pediatr Otorhinolaryngol 2009;73:1025-8.

24. Chin CH, Kirkness JP, Patil SP, et al. Compensatory responses to upper airway obstruction in obese apneic men and women. J Appl Physiol 2012;112:403-10.

25. Tantrakul V, Park CS, Guilleminault C. Sleep-disordered breathing in premenopausal women: differences between younger (less than 30 years old) and older women. Sleep Med 2012;13:656-62.

26. Malhotra A, Huang Y, Fogel R, et al. The male predisposition to pharyngeal collapse: the importance of airway length. Am J Respir Crit Care Med

Cite this article as: Inoshita A, Kasai T, Matsuoka R, Sata N, Shiroshita N, Kawana F, Kato M, Ikeda K. Agestratified sex differences in polysomnographic findings and pharyngeal morphology among children with obstructive sleep apnea. J Thorac Dis 2018;10(12):6702-6710. doi: 10.21037/ jtd.2018.11.09
2002;166:1388-95.

27. Kirkness JP, Peterson LA, Squier SB, et al. Performance characteristics of upper airway critical collapsing pressure measurements during sleep. Sleep 2011;34:459-67.

28. Shigeta Y, Ogawa T, Venturin J, et al. Gender- and age-based differences in computerized tomographic measurements of the orophaynx. Oral Surg Oral Med Oral Pathol Oral Radiol Endod 2008;106:563-70.

29. Wesström J, Ulfberg J, Nilsson S. Sleep apnea and hormone replacement therapy: a pilot study and a literature review. Acta Obstet Gynecol Scand 2005;84:54-7.

30. Shim GJ, Gherman D, Kim HJ, et al. Differential expression of oestrogen receptors in human secondary lymphoid tissues. J Pathol 2006;208:408-14.

31. Tagaya M, Nakata S, Yasuma F, et al. Children with severe or moderate obstructive sleep apnoea syndrome show a high incidence of persistence after adenotonsillectomy. Acta Otolaryngol 2012;132:1208-14. 